\section{EL MITO DE PIGMALIÓN EN TEXTOS LITERARIOS Y FÍLMICOS}

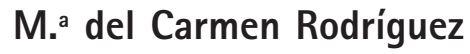

Universidad de Oviedo

\begin{abstract}
In this essay we will take Roland Barthes' definition of Myth as the starting point for the analysis of several classical and contemporary versions of the myth of Pygmalion. According to Barthes, myth is not eternal, it is transient and human history can subvert and deconstruct it. This is what happens with the contemporary versions of this myth. Opposed to the classical versions that insist on the gender construction, contemporary examples subvert the pygmalonian character, erasing him from the scene or the screen so that the oppressed characters become owners of their lives, articulated and empowered.
\end{abstract}

KEY WORDS: Myth; woman; education; articulation; deconstruction; film; literature.

El mito de Pigmalión, de origen semítico, aparece en la antigüedad bajo representaciones diferentes. La primera está recogida por Virgilio en el libro 1 de La Eneida; en ella, Pigmalión es rey de Tiro y hermano de Dido. La segunda referencia, más acorde con la denominación y el conocimiento que se ha trasmitido de este mito, corresponde a Clemente de Alejandría y aparece en Protrepticus. En esta obra Pigmalión aparece como un rey de Chipre que se enamora de una estatua de marfil que representa a una mujer esculpida por él mismo. La historia cuenta que en una fiesta de la diosa Afrodita, Pigmalión le pide a ésta que le conceda una esposa que se parezca a la estatua. Al regreso a su casa, la estatua ha cobrado vida, pudiendo ver Pigmalión cumplido su deseo (Grimal, 1984, 458-459). Igualmente el poeta latino Ovidio en su obra Metamorfosis cuenta la historia de este personaje, según la cual Pigmalión, rey de Chipre y escultor, había modelado una figura femenina tan hermosa que se enamoró de ella, Ilamándola Galatea. El relato coincide con el de Clemente de Alejandría, incluso en su petición a la diosa Afrodita y en la concesión de su deseo.

Por otra parte, también el relato bíblico de la creación de Adán y Eva comparte algunos elementos, siquiera tangencialmente, con la leyenda de este personaje, pues dice el

\section{THE MYTH OF PYGMALION IN LITERARY AND FILMIC TEXTS}

RESUMEN: En este estudio se tomará como punto de partida a Roland Barthes y su definición de mito en el análisis de versiones clásicas y contemporáneas del mito de Pigmalión. Para Barthes, un mito no es eterno, sino transitorio ya que el curso de la historia de los pueblos puede subvertirlo y deconstruirlo. Asi ocurre en las representaciones contemporáneas de Pigmalión. Al contrario de las versiones clásicas, que perpetúan la construcción de género, las obras más contemporáneas subvierten al personaje pigmalioniano, le restan importancia hasta hacerlo casi desaparecer, y son los personajes, en principio, subordinados quienes se forjan su educación hasta conseguir su articulación personal.

PALABRAS CLAVE: Mito; mujer; educación; articulación; deconstrucción; cine; literatura.

libro de "El Génesis": "[entre todos los animales] no había para el hombre ayuda semejante a él. Hizo, pues, Yavé Dios caer sobre el hombre un profundo sopor; y dormido, tomó una de sus costillas, cerrando su lugar con carne, y de la costilla que del hombre tomara, formó Yavé Dios a la mujer" ("El Génesis" 2: 20-23).

Todas estas leyendas tienen en común unos elementos en torno a los cuales se vertebró el planteamiento histórico de la superioridad masculina frente a la femenina, ya que, según la construcción cultural de Occidente, la mujer es creada o formada a partir de un varón, es inferior a él y carece de voz. Otorgan, por tanto, estos relatos una superioridad al hombre, haciéndole creador y modelador de la mujer mientras que a ella le corresponde el papel de ser la receptora de la sabiduría que él le va dictando, convirtiéndola en un personaje pasivo, sumiso y sin voz propia, pues recibe, interioriza y tiene que asumir como propio el conocimiento que le es trasmitido. Éste es el fundamento que subyace en la construcción de género y en el que se ha basado históricamente la relación hombre-mujer. Este principio identifica y define el mito de Pigmalión en nuestra cultura, como el de una relación desigual entre dos personas de distinto sexo en la que el varón, mayor en edad que la mujer y supuestamente más culto, la educa y, 
por tanto, la modela según unos cánones históricamente establecidos. De acuerdo con la definición que ofrece Roland Barthes en Mythologies:

Myth is a type of speech, everything can be a myth provided it is conveyed by a discourse. Myth is not defined by the object of its message, but by the way it utters this message. One can conceive of very ancient myths, but there are no eternal ones; for it is human history which converts reality into speech, and it alone rules the life and the death of mythical language (Barthes, 1972, 109-110).

Según Barthes, Pigmalión es un mito puesto que la historia se ha servido de esta leyenda para hacerle trasmisor de un mensaje, aquél que concede capacidad de actuación a un ser masculino sobre una representación femenina, estática y $\sin$ voz, ya sea escultórica o literaria. Ahora bien, en cuanto que un mito es un modo de hablar, un mito no es eterno porque es la historia la que lo verbaliza y la que rige la vida y la muerte del lenguaje mítico. Por tanto es transitorio, como se verá en este análisis sobre modelos pigmalionianos en la escena y el cine.

Un mito se puede sustentar secularmente de acuerdo con una construcción social de género interesada para algunos; pero no por ello es eterno, ya que el curso de la historia filosófico-social de los pueblos puede subvertirlo y deconstruirlo. Como parte de esta deconstrucción se utilizan unos recursos para solicitar, lo que Barthes Ilama "la emancipación del mito". En los ejemplos que se utilizarán en este análisis, esta emancipación consiste en liberar a los personajes afectados por cuestiones de género y clase procurándoles una educación que les permita afrontar su vida independientemente de los demás y no sintiéndose subordinados a quienes fueran sus educadores.

El premio Nobel de Literatura George Bernard Shaw escribió en 1914 la obra de teatro Pygmalion. En ella, el profesor Higgins, de clase alta y especialista en fonética, toma bajo su responsabilidad la educación de Eliza Doolittle, una florista de baja extracción social, con el fin de enseñarla a hablar correctamente. La pieza teatral de Bernard Shaw obtuvo un gran éxito y se benefició del auge que alcanzaron en el primer tercio del siglo XX el teatro y el cine como espectáculos de masas. De esta obra surgiria su más famosa versión fílmica en 1964, My Fair Lady, dirigida por George Cukor. No obstante, el tema pigmalioniano fue de gran interés como lo demuestra el hecho de que con anterioridad a la obra de Shaw ya hubiera versiones literarias, musicales, operísticas y dancísticas del mito. Pigmalión aparece en el cine tan pronto como éste se consolida como un medio de expresión artística con capacidad narrativa. La primera película sobre este mito de la que se tiene constancia es del director francés George Melies de 1903. La segunda tiene también origen galo; su director es Daniel Riche y data de 1909. Dos años más tarde, en 1911, aparece la primera versión del mito de factura inglesa. Se trata de The Modern Pygmalion and Galatea de los directores Walter R. Booth y Theo Frenke'. En 1938 se realiza Pygmalion, dirigida por Anthony Asquith y Leslie Howard, también de producción británica. A partir de este momento, coincidiendo con la etapa de esplendor del cine clásico, la historia de la joven humilde e ignorante, que es rescatada de sus orígenes y convertida en una joven dócil y educada, se prodiga bajo manifestaciones muy diferentes, según el momento y la casuística. Los ejemplos abundan en el cine y pueden ser desde Rebecca (A. Hitchcock, 1940), en la que la joven e innominada esposa es "educada" para la vida matrimonial, en contraposición a Rebecca, mujer díscola y mundana que la precedió en Manderley, hasta Pretty Woman (G. Marshall, 1990), historia en la que un hombre de negocios de gustos refinados alquila los favores de una prostituta, brindándosele a ésta la oportunidad de abandonar temporalmente las calles.

En la vastísima producción de películas hay abundantes ejemplos que tratan, abierta o subliminalmente, el tema pigmalioniano y sus múltiples variantes, puesto que, a lo largo de la historia, las mujeres carecieron de las mismas oportunidades en materia educativa que los hombres al planteárseles como objetivo principal de su existencia el matrimonio y las obligaciones inherentes al mismo, y recibir una educación para este fin, por lo que hasta bien entrado el siglo XX no hubo un acceso a una formación que las educara en igualdad de condiciones que a los varones, cerrándoseles las puertas al desempeño de unas tareas en la esfera pública $y$, por tanto, impidiéndoseles su plena articulación personal. Hubo por ello innumerables ejemplos que ilustran esta situación de desigualdad, invisibilidad y silencio. Dado el carácter expansivo del cine, estas reiteradas asunciones de desequilibrio y de subordinación en las relaciones heterosexuales resultaron sumamente dañinas. A ellas se opusieron las teóricas feministas cinematográficas, reivindicando nuevos modos de filmar y de 
representar a los personajes femeninos de manera asertiva y articulada.

Además, el mito de Pigmalión guarda estrecha relación con el arquetipo de Cenicienta, "la joven condenada a vivir menospreciada y oprimida, pero a la que finalmente le es reconocida su bondad" (Fernández, 1997, 27), pues como dice $\mathrm{C}$. Fernández en su estudio "Cenicienta constituye la expresión literaria de la que es una de las premisas básicas del sistema patriarcal: toda mujer ha de buscar su autorrealización en el matrimonio $y$, en concreto, en las funciones a las que éste la destina, que no son sino las de la maternidad y el trabajo doméstico" (Fernández, 1997, 134). Estos principios han constituido los fundamentos de la construcción social de género que el cine de Hollywood difundió reiteradamente hasta bien entrada la década de los sesenta y con los que todavía en la actualidad sorprende a los espectadores ocasionalmente.

Por tanto no extraña al público espectador que sea el varón quien, al ofrecerle al personaje femenino un status económico y social superior, sirva de guía a la mujer y se erija en su portavoz y héroe salvador. El ejemplo más conocido es el ya citado de Pretty Woman, donde el personaje masculino, encarnado por Richard Gere, enseña a Julia Roberts, en el papel de prostituta, a comportarse en sociedad para redimirla posterior y definitivamente de las calles y convertirla en su esposa.

A pesar de que diversos modelos de Pigmalión estén todavía muy presentes en las sociedades contemporáneas bajo diferentes manifestaciones eurocéntricas, fundamentadas en la errónea idea de la superioridad del hombre sobre la mujer, de la raza blanca frente al resto de las razas, del norte sobre el sur, etc., para contrarrestar y mostrar la deconstrucción de este mito se va a analizar la obra del dramaturgo de Liverpool, Willy Russell, Educating Rita (1980) y su versión cinematográfica con el mismo título, dirigida por Lewis Gilbert en 1983. Todavía va más lejos la película Billy Elliot (Stephen Daldry, 2000). En ella, el papel de educador está encarnado por una profesora de baile y el de la persona a educar es, en esta ocasión, un niño que, procediendo de una familia minera de las montañas del norte del país, aspira a ir a Londres y hacer carrera allí como bailarín. En una vuelta de tuerca más, el papel de la educadora está encarnado por la actriz Julie Walters, quien en Educating Rita fuera el personaje femenino que busca su superación y articulación. Así pues nos encontramos ante un mito del que se han hecho múltiples y muy variadas adaptaciones en cuanto a los géneros utilizados y a su evolución histórico-social.

Varias han podido ser las fuentes de donde bebieran los cineastas que llevaron este mito al cine. Se han hecho representaciones teatrales, que dieron lugar posteriormente a la película de Asquith y Howard en $1938^{2}$. En los años cincuenta se hizo una comedia musical en Broadway con el título de My Fair Lady que, unos años más tarde, sería llevada al cine por George Cukor ${ }^{3}$. En los años setenta se reestrenó de nuevo el musical en Broadway. En 2007 hubo una nueva reposición de esta pieza que estuvo de gira por diversas ciudades estadounidenses. En la actualidad la actriz y guionista Emma Thompson es la encargada de escribir el guión para un remake de la película de Cukor y del musical de Broadway adaptándolo a los gustos contemporáneos.

Ante la imposibilidad de analizar este amplio corpus cinematográfico en su totalidad, este estudio se centrará en la emancipación de los sometidos de la que habla Barthes: por un lado, referida al uso que hacen de la voz, no sólo como parte esencial de su educación, de acuerdo con unos patrones preestablecidos, sino por la capacidad que muestran estos personajes para verbalizar su evolución hacia un posterior empoderamiento en las diferentes versiones del mito. Por otra parte, también se verá cómo su capacidad de movimiento y adquisición del espacio dentro del campo visual incide positivamente en el logro de su aserción personal. Finalmente, habrá un breve apartado dedicado a la comunicación dancística en Billy Elliot, la versión más transgresora de Pigmalión.

\section{Versiones clásicas de Pigmalión}

Como ya se ha apuntado, los orígenes de este mito aparecen en la literatura escrita en testimonios tan antiguos como La Eneida, La Metamorfosis o Protrepticus. De igual modo, existen versiones fílmicas anteriores a la versión literaria de Shaw, por lo que indudablemente ha existido un interés por dar a conocer y diseminar los valores que representa este mito en la cultura occidental desde los comienzos de la literatura escrita y el cine. Dada la corta 
extensión que tenían las películas de los primeros directores y las dificultades técnicas del cine primitivo no es difícil suponer que aquellos filmes no tendrian una duración superior a varios minutos, con lo cual el argumento de aquellos primeros Pigmaliones cinematográficos carecerían de muchos de los elementos con los que se rodeó la obra de Shaw, que, a buen seguro, supera ampliamente las expectativas creadas en las obras de los primeros cineastas. Lo que sí queda patente de aquellas filmaciones es que desde sus origenes la literatura y el cine han compartido "el territorio intangible de los sueños" del que habla Gonzalo Suárez y que, dentro del imaginario masculino, parte de estos sueños anhelaban controlar a la figura femenina para hacerla suya y divulgar un modo de comportamiento que interesaba a sus congéneres.

En la literatura hay abundantes ilustraciones de este interés por la educación de las mujeres a manos de sus parejas masculinas: desde la figura de la casada indómita, en sus versiones literarias española e inglesa de Don Juan Manuel (De lo que contesçió a un mançebo que casó con una mujer muy fuerte e muy brava) y de William Shakespeare (La fierecilla domada) respectivamente, hasta los correctivos que sufrian las adúlteras en las novelas del siglo XIX, el cine y la literatura están repletos de ejemplos que sirven de modelo a la sociedad, sin perder de vista que es en la sociedad donde encuentran la mayor parte de los escritores y directores las historias para sus argumentos. Habida cuenta de la potencial influencia que tenia el cine por ser capaz de reunir a cientos de personas en una misma exhibición, no extraña que éste, en cuanto alcanzó la extensión necesaria para desarrollar su capacidad narrativa, se nutriera de la literatura en busca de argumentos atractivos y que de ahí surgiera un cine de ficción con un desarrollo de géneros y con unos intereses formales y temáticos similares. Surgen así las adaptaciones ${ }^{4}$ de una manifestación artística determinada en otra nueva que, en el caso del teatro y el cine poseen además elementos comunes que facilitan el trasvase, como son la escenificación, la duración similar de las obras y su representatividad. Para el crítico Sánchez Noriega la adaptación se puede definir como:

El proceso por el que un relato, la narración de una historia, expresado en forma de texto literario, deviene, mediante sucesivas transformaciones en la estructura (enunciación, organización y vertebración temporal), en el contenido narrativo y en la puesta en imágenes (supresiones, compren- siones, añadidos, desarrollos, descripciones visuales, dialoguizaciones, sumarios, unificaciones o sustituciones), en otro relato muy similar expresado en forma de texto fílmico (Sánchez Noriega, 2000, 47).

Sánchez Noriega considera que ha habido unas razones que promovieron la necesidad de adaptar la literatura al cine: la urgencia de historias, la garantía de éxito comercial, el acceso al conocimiento histórico y la recreación de mitos y obras emblemáticas, el prestigio artístico y cultural y, finalmente, la labor divulgadora (Sánchez Noriega, 2000, 50-52). De entre estas razones, la garantía de éxito de las representaciones teatrales y musicales que precedieron a las dos adaptaciones filmicas, la recreación de un mito y el prestigio artístico y cultural de la obra de un premio Nobel de literatura no dejan lugar a dudas acerca de las razones que pudieron haber motivado la transposición del Pygmalion de Bernard Shaw al cine. Las dos versiones cinematográficas, tanto la de 1938 como la de 1964, venían avaladas por un triunfo de público y crítica que hacian fácilmente suponer el éxito de taquilla en el cine. Por otro lado, los mitos se han recreado y revisado en el cine periódicamente, como si existiera una necesidad acuciante de acercar a las sucesivas generaciones el conocimiento de aquéllos o de mantener, al menos, vivo su recuerdo y significado. A esto hemos de añadir que el propio Bernard Shaw tomó parte activa en las adaptaciones de su obra, negándose a que el cine retocara sus piezas teatrales por el miedo a que con la adaptación se perdieran los conceptos y los énfasis que él había empleado, por lo cual el éxito de estas adaptaciones estaba sobradamente garantizado ${ }^{5}$.

De acuerdo con la definición de adaptación que da el profesor Sánchez Noriega, la película de 1938 sigue fielmente la estructura del texto literario en su enunciación, organización y vertebración temporal. Añade varias secuencias dedicadas al duro aprendizaje fonético e incorpora una secuencia de una fiesta organizada en una embajada, donde los profesores Higgins y Pickering ponen a prueba a la nueva señorita Doolittle. La versión de 1964 excede con mucho la extensión de la anterior, sin embargo es también una versión fidedigna del texto literario, con la excepción de que al tratarse de una adaptación de una comedia musical tiene muchos números de baile y canto.

Desde una perspectiva de género, tanto la obra de Shaw como estas dos versiones, de 1938 y de 1964, merecen 
nuestra crítica por la actitud misógina de Higgins, que ya queda patente cuando, a instancias del coronel Pickering, dice a propósito de las mujeres:

Pickering: "Excuse me the straight question, Higgins. Are you a man of good character where women are concerned?" Higgins: "Have you ever met a man of good character where women are concerned?"

Pickering: "Well, I haven't. I find that the moment I let a woman make friends with me, she becomes jealous, exacting, suspicious, and a damned nuisance. I find that the moment I let myself make friends with a woman, I become selfish and tyrannical. Women upset everything. When you let them into your life, you find that the woman is driving at one thing and you're driving at another" (Shaw, 1916, 50).

Tampoco pasa desapercibido el tono, a veces hiriente a veces paternalista, que se utiliza hacia la joven. Así, en el acto IV, cuando ya Eliza ha superado la prueba de hacerse pasar por una mujer noble y educada, le dice su pigmalión:

Higgins: "The creature is nervous afier all... Ah! Would you? Claws in, you cat... Why have you begun going on like this? May I ask whether you complain of your treatment here? Has anybody behaved badly to you?... You go to bed like a good girl and sleep it off. Have a little cry and say your prayers" (Shaw, 1916, 105-106).

De igual modo es reprobable en su conjunto la educación que está recibiendo Eliza. El personaje es sólo un objeto de estudio dentro de la investigación que llevan a cabo los fonetistas y a la que no se la está enseñando a tener ideas propias ni se la está formando para que pueda argumentar sus opiniones y participar en una conversación racional y lógica con otras personas. Sólo se la enseña a pronunciar y entonar correctamente para que pueda hablar trivialmente del tiempo y de la salud. Ni Higgins ni Pickering tienen en consideración las palabras de Mrs. Pierce (el ama de llaves) o Mrs. Higgins (la madre del profesor) cuando a lo largo de la obra toman partido por Eliza; sus opiniones les pasan inadvertidas. Así dice Mrs. Pierce en el acto segundo:

Higgins: "What's the matter?"

Mrs. Pierce: "Well, the matter is, sir, that you can't take a girl up like that as if you were picking up a pebble on the beach... Will you please keep to the point, Mr. Higgins. I want to know on what terms the girl is to be here. Is she to have any wages? And what is to become of her when you've finished your teaching?" (Shaw, 1916, 44)

Por su parte, Mrs. Higgins le dice a su hijo:

Mrs. Higgins: "A problem... No, you two infinitely stupid male creatures: the problem of what is to be done with her afterwards".

Higgins: "I don't see anything in that. She can go her own way, with all the advantages I have given her".

Mrs. Higgins: "The advantages of that poor woman who was here just now! The manners and habits that disqualify a fine lady from earning her own living without giving her a fine lady's income" (Shaw, 1916, 87).

Esta preocupación de Mrs. Higgins la comparte también Eliza, quien, una vez alcanzados los propósitos de Higgins y Pickering se estremece al escuchar las palabras de Higgins: "Thank God it's over!" que la hace reflexionar primeramente acerca de su incierto futuro y de sus propias posibilidades más adelante, cuando le dice a Higgins:

Eliza: "What am I fit for? What am I to do?... Your calling me Miss Doolittle that day when I first came to Wimpole Street. That was the beginning of self-respect for me. No, not now. Never again. I have learnt my lesson. I don't believe I could utter one of the old sounds if I tried... Oh! If I only could go back to my flower basket! I should be independent of both you and father and all the world! Why did you take my independence from me? Why did I give it up? I'm a slave now for all my fine clothes..

Higgins: "What'll you teach, in heaven's name?"

Eliza: "What you taught me. I'll teach phonetics" (Shaw, 1916, 134-35).

La educación de Eliza no se limita a pronunciar los sonidos perfectamente sino que en el curso de su aprendizaje ha logrado articularse como persona pues da a conocer sus pensamientos, se muestra asertiva y se enfrenta a su creador, mostrándose, a su vez, como una hipotética fonetista. Sin embargo, la articulación total, aquella que ha de convertirla en una mujer plena e independiente, no se logra en estas versiones clásicas del mito pues en las adaptaciones filmicas se busca un final feliz que poco tiene que ver con las tesis que el dramaturgo irlandés declara en el epílogo.

ARBOR CLXXXVI 741 enero-febrero [2010] 33-42 ISSN: 0210-1963

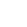


Éste es uno de los aspectos más llamativos de la obra, ya que la postura de Bernard Shaw con respecto a las perspectivas que se le ofrecian a Eliza difiere del final que se propone en la versión de 1938 (en la que él había participado), con un desenlace precipitado, sin sentido y humillante para las mujeres. En la versión de 1964 esta fricción de los protagonistas se alivia mediante sus canciones, que tienen el doble propósito de dar mayor lucimiento a Audrey Hepburn y Rex Harrison a la vez que espacian estos momentos de tensión emocional. Pero el desenlace nada tiene que ver con el propósito ideológico que el dramaturgo ofrece en el epílogo que él añade a la pieza teatral. Shaw manifiesta en este apéndice la imposibilidad de que Eliza Doolittle sea finalmente la esposa de Higgins, especialmente porque Higgins no tiene un interés por ella y porque Eliza evoluciona en la obra hasta desear independizarse y abrirse camino profesionalmente.

Dice el autor en este apéndice final:

Eliza, in telling Higgins she would not marry him if he asked, was not coquetting: she was announcing a well considered decision. When a bachelor interests, and dominates, and teaches, and becomes important to a spinster, as Higgins with Eliza, she always, if she has character enough to be capable of it, considers very seriously indeed whether she will play for becoming that bachelor's wife, especially if he is so little interested in marriage that a determined and devoted woman might capture him if she set herself resolutely to do it (Shaw, 1916, 140) (mi énfasis).

Si se parte del interés de Shaw por preservar el espíritu de su obra y se tiene en cuenta la misoginia del personaje de Higgins, alter ego de Shaw, su alocución final no deja dudas acerca de la consideración que le merecen las mujeres. Por ello, desde una perspectiva de género se plantea la siguiente cuestión: ¿Cómo, tras manifestar Eliza su deseo por ser independiente, bien teniendo una tienda de flores, bien como profesora de fonética, y después de protagonizar una escena de humillaciones constantes, va a ofrecerse el personaje para ser su esposa y atender a Higgins servilmente? Sólo hay una respuesta y ésta tiene mucho que ver con los propios intereses cinematográficos: con el Código de censura Hays y con el propósito de Hollywood de que las películas fueran moralizantes y sirvieran de ejemplos al público que abarrotaba las salas ${ }^{6}$. De la influencia que Shaw continuó ejerciendo después de su muerte (1950), baste decir que cuando Alan Jay Lerner y Frederick Loewe adaptaron la obra a los escenarios de Broadway, se decidieron por dar otro título a la comedia musical de 1956 y a la versión fílmica de 1964 para evitar así la coincidencia con la obra shawiana (Romaguera y Alsina, 442).

\section{RELECTURAS CONTEMPORÁNEAS: EDUCATING RITA Y BILLY ELLIOT}

En Educating Rita el personaje de Susan o Rita, nombre que ella adopta en un intento por emular a una escritora de novela popular romántica, desea sobrepasar las barreras que la sociedad ha creado a su alrededor y salir del espacio que la reduce al estatus de mujer casada de clase trabajadora. La obra está construida en clave de comedia y el personaje de Rita, en la versión fílmica encarnado por Julie Walters, cautiva al público espectador por su inocencia, su discurso sencillo y coloquial y por su gana de aprender de Frank, su profesor de literatura. Del personaje masculino se encarga Michael Caine, cuya magnifica deconstrucción del personaje pigmalioniano le valió, igual que a Julie Walters, la nominación al Oscar en 1983.

La gran diferencia con las versiones clásicas del mito es que en Educating Rita es el personaje femenino quien busca su educación antes de acceder a los compromisos y responsabilidades que la sociedad le tiene asignados por su condición femenina. Para ello acude a un curso de literatura que ofrece la Open University británica. Su profesor, Frank, subvierte la idea que se tiene de un profesor universitario: no tiene ningún interés por la investigación ni por la docencia, es un hombre frustrado, casi estático, que sólo sale de su despacho por necesidades del argumento y la dramatización de la obra. Rita también subvierte su papel social pues aunque trabaje como peluquera no pierde un instante para leer, ya sea en el trabajo, en el autobús o en su casa mientras su marido pega martillazos para tirar una pared. El personaje de Rita sabe qué es lo que desea para sí: quiere una vida diferente, una vida que de momento sólo imagina en las novelas románticas y populares que lee. Quizá éstas no sean el mejor ejemplo para lo que ella desea, pero sí son las únicas que le ofrecen alternativas a la vida sin horizontes esperanzadores que tiene de momento y constituyen su único acceso a los libros. Por eso da el importantísimo paso de matricularse en un curso de lite- 
ratura dentro de un programa de la universidad abierta. El hecho de que se trate de unos estudios a distancia y no sea un programa de enseñanza normalizada, no puede pasar desapercibido desde una perspectiva feminista porque Rita no desea un aprendizaje rígido y canónico, ni comprimido por unos créditos repartidos entre enseñanzas variadas. Rita quiere tener igual acceso a la educación que las personas de otro sexo y clase, pero necesita hacerlo fuera de los muros institucionales, donde nunca se le permitiría asumir su condición de mujer valiente, sin limitaciones ni cortapisas, y articular plenamente su vida.

Si en la obra de Shaw prácticamente toda la historia transcurre en la casa del profesor, donde Eliza recibe una especie de inmersión lingüística-educativa para señoritas, en la obra de Russell Rita busca esta formación en la literatura; para lo que ha de ir traspasando las barreras culturales de clase y género. Desde la primera secuencia, en la que llega a la universidad y entra por un pasillo estrecho y oscuro, sin olvidar la resistencia de la puerta del despacho de Frank que ella abre de un empujón, sin que él se levante de su asiento para ayudar, el movimiento espacial de la protagonista y la luz u oscuridad que recibe simbolizan desamparo, pero, a su vez, su capacidad de aserción personal.

Uno de los aspectos que quisiera mencionar brevemente es la forma de vestir que tienen Eliza y Rita. En las versiones clásicas, el personaje viste de manera chillona a su llegada a la casa de Higgins y éste manda quemar su ropa y se le encargan vestidos nuevos, sobre los que ella no tiene ninguna capacidad de decisión. En Educating Rita, la ropa forma parte del proceso de aprendizaje de la protagonista. En cada escena viste y aparece peinada de manera diferente; de este modo, se llama la atención del público espectador sobre el desarrollo del personaje y de su interés por encontrar su propio estilo, acorde con la nueva mujer que se está creando. De igual manera, según va evolucionando y haciéndose culta, Rita va cambiando su manera de hablar. Su acento y entonación liverpuldiana no es nunca motivo de corrección por parte de Frank; al contrario, cuando Rita adopta temporalmente un tono afectado, Frank le pregunta por qué habla así. Relacionado con su manera de vestir y de hablar, hay una escena representativa de su soledad y de su búsqueda de identidad que ocurre cuando Frank invita a Rita a una velada en su casa y ella se prueba ante el espejo diversos vestidos para saber qué modelo es el más indicado, a la vez que ensaya diferentes temas de conversación. Rita no se identifica con las representaciones del espejo, de ahí que la escena finalice desechando los trajes y los clichés de conversación, consciente de que ha de ser ella misma y, por tanto, hablar su propio lenguaje. Si ella hubiera asistido a casa de Frank con una cuidada elección de su apariencia, se equipararía al personaje clásico, pues se haría de ella un estereotipo de cómo debe de vestir y comportarse una mujer. Pero, tanto en el caso de Russell como en el del director del filme, no es esto lo que quieren para su personaje femenino. Ellos buscan ofrecer al público una nueva imagen de mujer, moderna y asertiva que no se deja encorsetar por la sociedad y que necesita alcanzar su articulación personal para tomar decisiones sobre su vida.

El movimiento adquiere una importancia especial en las subversiones del mito porque su capacidad de acción está estrechamente ligada a la aserción y el empoderamiento que necesitan los que están en situación de inferioridad. Si en las versiones clásicas Eliza apenas se salía del guión preestablecido y actuaba como una muñeca en manos de Higgins y Pickering, no ocurre así en las versiones contemporáneas. Especialmente importante en Educating Rita es la secuencia central de la obra cuando Rita se da cuenta de que está desplazada respecto a los de su clase social y tampoco encaja en la velada en el domicilio de Frank. Rita sale de su casa sola, camina por un oscuro pasadizo lateral para peatones por debajo de un puente, viaja en autobús a otro barrio de la ciudad y cuando llega a la casa, mira hacia arriba y ve a los invitados departiendo amistosamente. La luz de la calle proyecta sobre su pecho la sombra de las verjas que dan acceso al edificio. No hay nada que aparentemente impida a Rita entrar en la casa de Frank, sin embargo, la sombra de las verjas simbolizan su temor a no ser aceptada por pertenecer a la clase trabajadora y no tener una conversación adecuada. Rita abandona la escena cabizbaja y se dirige al pub donde están su marido, sus padres y otros amigos festejando el próximo matrimonio de su hermana pequeña. Antes de entrar en el bar, Rita mira por el cristal de la puerta, que, de nuevo, simboliza una barrera invisible que evoca el desplazamiento y el distanciamiento de los suyos en este punto de su formación; Rita pasa al interior, es recibida efusivamente por su marido y se sienta al lado de su madre; todos cantan a coro el estribillo de la canción que sale de la máquina de discos que dice "We're so happy together", Rita mira a su madre

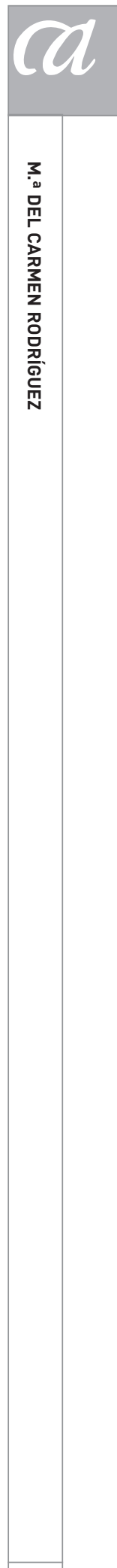


que está sollozando y le pregunta qué le pasa; la madre dice "There must be better songs to sing". Estas palabras le sirven a Rita de revulsivo para volver a sus libros y avanzar en su voluntad por lograr ser ella misma, para poder decidir acerca de su futuro sin necesidad de aceptar las imposiciones sociales, lo que logra finalmente al aprobar sus exámenes con éxito. En una de sus últimas alocuciones dice: "Ahora puedo elegir, puedo ir a la escuela de verano, puedo ir al sur de Francia, puedo ir a Londres, puedo ser madre o también puedo volver a la peluquería".

Educating Rita es una deconstrucción total del mito de Pigmalión pues ni Frank, como educador, ni Rita, como figura a modelar, cumplen con su parte. Ella no es ni silenciosa ni estática sino vivaz y habladora. Frank no tiene ningún interés por educar a Rita como él piensa que debería de hacerlo; sí le facilita, en cambio, las herramientas para que ella se labre su propia formación. Como él le dice, casi al final de la película y del texto teatral, comparándose con Mary Shelley y asociándola a ella a su obra Frankenstein, Rita supera a su creador.

En el año 2000 Stephen Daldry dirige Billy Elliot, filme que ofrece una nueva versión del mito clásico. Billy, un niño huérfano de madre, vive en un ambiente asfixiante para él: su abuela demente y su padre y su hermano mineros no comprenden que él rechace las clases de boxeo y, por el contrario, vaya a aprender ballet con el grupo de niñas de su escuela. La profesora del grupo de jovencisimas bailarinas es la Sra. Wilkinson (encarnada por Julia Walters), actriz protagonista en Educating Rita, quien, en su papel de educadora, limita su función a acoger a Billy, enseñarle junto a su grupo de alumnas y facilitarle un impreso de solicitud para que pueda proseguir sus estudios en Londres. Desde el punto de vista del mito, esta película va un paso más allá en su deconstrucción. En primer lugar hay una inversión de papeles: no existe Pigmalión, que ya no es un hombre sino una mujer; pero ésta no enseña, no modela a una figura estática, todo lo contrario: enseña a un niño, al que no se le educa para que aprenda a relacionarse en sociedad, según unos patrones preestablecidos, sino a hacer valer sus propias opiniones y a saber elegir. Son su familia, sus vecinos y los espectadores asistentes a la función dancística quienes han de aprender a entender el lenguaje de la danza como un modo de expresión corporal que dé rienda suelta a las especificidades y diferencias sexuales de los individuos. Si en Educating Rita, la protagonista se siente desplazada socialmente y busca en el cambio permanente de su físico y de los espacios su ubicación como mujer contemporánea, en Billy Elliot el personaje carece de una figura referencial; se encuentra también solo y la frustración que esto le provoca hace que arremeta con sus piernas contra todo lo que hay a su alrededor y da patadas a las paredes, desafiando las restricciones, aparentemente invisibles, que se le pretenden imponer como varón e hijo y hermano de mineros que desea ser bailarín de ballet clásico.

A través de los ejemplos elegidos para ilustrar la evolución del mito de Pigmalión en el siglo XX, la figura patriarcal de la primera mitad del siglo ha dado paso a un personaje masculino o femenino, cuya responsabilidad para educar se limita a ofrecer las herramientas que hagan posible la articulación de la persona o del personaje sin excederse en sus atribuciones ni superproteger a quien busca poder verbalizar por medio de palabras y de sus actuaciones su definición personal. Shaw no deja de ser el primer Pigmalión de toda esta serie de versiones y subversiones concatenadas cuando escribe su obra teatral, pues excede las posibilidades del propio texto dejando un apéndice a modo de testamento vital que establece las razones por las que Eliza ha de comportarse del modo que él piensa para ella, lo que le convierte en un manipulador que quiere extender su poder más allá de su obra. Con esto limita las posibilidades a los futuros directores de su pieza teatral sobre los escenarios o en sus versiones fílmicas. Por su parte, el personaje de Higgins, el alter ego de Shaw, decide acerca de cada aspecto de la educación de Eliza, no dejando espacio para una interpretación menos encorsetada de su obra. Habrian de ser Willy Russell, Lewis Gilbert $y$, posteriormente, Stephen Daldry quienes subvierten el mito clásico, la superioridad cultural de los hombres sobre las mujeres y también de éstas sobre aquéllos para ir desapareciendo gradualmente y dejar en manos de cada individuo la responsabilidad de que cada cual se forje la educación que para sí desee y convertirse en personas articuladas que se han emancipado de los mitos construidos históricamente. 
VERSIONES DE PIGMALIÓN EN LA LITERATURA, LA DANZA, LA ÓPERA, LA COMEDIA MUSICAL Y EL CINE

1 Las primeras películas, dada su corta extensión, no se han utilizado para este análisis pues en una extensión de dos o tres minutos apenas puede haber narración argumental.

2 La película de Asquith y Howard tuvo cuatro nominaciones al Oscar a la mejor película, mejor actor, mejor actriz y mejor guión, consiguiendo finalmente el Oscar al mejor guión.

3 El film de Cukor My Fair Lady resultó todo un éxito con doce candidaturas al Oscar y finalmente ocho estatuillas a la mejor película, mejor director, mejor actor, mejor fotografia, mejor sonido, mejor adaptación musical, mejor decoración color y mejor vestuario color.

4 Remito a los lectores interesados a la lectura de Sánchez Noriega, cuya obra De la literatura al cine es un magnífico estudio necesario para toda aquella persona interesada por la adaptación.

5 No le faltaban a B. Shaw razones para preservar su obra pues a pesar del empeño puesto en ello y de ser coguionista de la versión fílmica de 1938 tuvo que permitir un "final feliz" acorde con los dictados de la época que poco podía satisfacer al dramaturgo a tenor de lo escrito en el epílogo de su obra.

6 Para más información, véase Diosas del celuloide. Arquetipos de género en el cine clásico. Rodríguez, C. editora. Madrid, Jaguar, 2007, donde se estudian los arquetipos femeninos en el cine de Hollywood y el poder patriarcal del cine y su incidencia en las sucesivas gene-

Recibido: 10 de octubre de 2008 Aceptado: 9 de diciembre de 2008 raciones de espectadoras y espectadores.
Pygmalion, 1693, ópera de Johann Georg Conradi.

Pygmalion, 1748, ópera de Jean-Philippe Rameau.

Pygmalion, 1762, pieza teatral de JeanJacques Rousseau.

Pygmalion (XVIII), un duodrama ópera de Georg Anton Benda.

Il Pigmalione, 1816, ópera de Gaetano Donizetti.

Pygmalion and Galatea, 1871, pieza teatral de W. 5. Gilbert.

Galatea, or Pygmalion Reversed, 1883, comedia musical de Meyer Lutz.

Pygmalion, ou La Statue de Chypre (Pygmalion, or The Cyprus Statue), 1883, ballet con coreografía de Marius Petipa. Bernard Shaw.

Pygmalion, 1938, película basada en la obra de George Bernard Shaw.

My Fair Lady, 1956, comedia musical y, 1964, película de Alan Jay Lerner y Frederick Loewe basada en la obra de Shaw.

\section{BIBLIOGRAFÍA}

Barthes, Roland (1972): Mythologies, Londres, Paladin Granada Publishing, 1984.

Fernández Rodríguez, Carolina (1979): Las re/escrituras contemporáneas de Cenicienta, Oviedo, KRK.

Grimal, Pierre (1984): Diccionario de mitología griega y romana, Barcelona, Buenos Aires, México, Paidós.

Rodríguez Fernández, M. Carmen (2006): "Educating Rita de Willy Russell: espacios y barreras socioculturales en un bildungsroman", Mujeres, espacio
Pygmalion, 1912, pieza teatral de George 
y poder (ed. Mercedes Arriaga Flórez et al.), Sevilla, Arcibel Ediciones, pp. 583-594.

Romaguera, J. y Alsina, R. (1993): Textos y manifiestos del cine, Madrid, Cátedra.

Russell, Willy (1980): Educating Rita, Londres, Methuen Drama.
Sánchez Noriega, José Luis (2000): De la literatura al cine. Teoría y análisis de la adaptación, Barcelona, Buenos Aires, México, Ediciones Paidós.

Shaw, George Bernard (1916): Pygmalion, Londres, Penguin Books, 1941.

Suárez, Gonzalo: "Dos cabalgan juntos", Academia n. 12 , octubre, 1995.

\section{FILMOGRAFIA}

Billy Elliot (Dir. Stephen Daldry, 2000).

Educando a Rita (Educating Rita, Dir. Lewis Gilbert, 1983).

My Fair Lady (Dir. George Cukor, 1964).

Pygmalion (Dir. Anthony Asquith y Leslie Howard, 1938). 